\title{
Laparoscopic appendectomy under spinal anesthesia with dexmedetomidine infusion
}

\author{
Go-Woon Jun ${ }^{1}$, Min-Su Kim ${ }^{1}$, Hun-Ju Yang ${ }^{1}$, Tae-Yun Sung ${ }^{1}$, Dong-Ho Park ${ }^{1}$, Choon-Kyu Cho ${ }^{1}$, \\ Hee-Uk Kwon ${ }^{1}$, Po-Soon Kang ${ }^{1}$, and Ju-Ik Moon ${ }^{2}$ \\ Departments of ${ }^{1}$ Anesthesiology and Pain Medicine, ${ }^{2}$ Surgery, Konyang University Hospital, Konyang University College of Medicine, \\ Daejeon, Korea
}

Background: Laparoscopic appendectomy (LA) is rarely performed under regional anesthesia because of pneumoperitoneum-related problems. We expected that dexmedetomidine would compensate for the problems arising from spinal anesthesia alone. Thus, we performed a feasibility study of spinal anesthesia with intravenous dexmedetomidine infusion.

Methods: Twenty-six patients undergoing LA received spinal anesthesia with intravenous dexmedetomidine infusion. During surgery, the patient's pain or discomfort was controlled by supplemental fentanyl or ketamine injection, and all adverse effects were evaluated.

Results: No patient required conversion to general anesthesia, and all operations were completed laparoscopically without conversion to open surgery. Seventeen (65.4\%) patients required supplemental injection of fentanyl or ketamine. Bradycardia occurred in seven (26.9\%) patients.

Conclusions: Spinal anesthesia with dexmedetomidine infusion may be feasible for LA. However, additional analgesia, sedation, and careful attention to the potential development of bradycardia are needed for a successful anesthetic outcome. (Korean J Anesthesiol 2014; 67: 246-251)

Key Words: Dexmedetomidine, Laparoscopic appendectomy, Spinal anesthesia.

Received: March 18, 2014. Revised: 1st, April 30, 2014; 2nd, June 11, 2014; 3rd, July 6, 2014. Accepted: July 7, 2014.

Corresponding author: Tae-Yun Sung, M.D., Department of Anesthesiology and Pain Medicine, Konyang University Hospital, Konyang University College of Medicine, 158, Gwangeodong-ro, Seo-gu, Daejeon 302-718, Korea. Tel: 82-42-600-9316, Fax: 82-42-545-2132, E-mail: unt1231@naver.com

(c) This is an open-access article distributed under the terms of the Creative Commons Attribution Non-Commercial License (http:// creativecommons.org/licenses/by-nc/3.0/), which permits unrestricted non-commercial use, distribution, and reproduction in any medium, provided the original work is properly cited. 


\section{Introduction}

With recent technical advances, acute appendicitis is more commonly performed under laparoscopy than by open laparotomy. Laparoscopic appendectomy (LA) has shown to haveconsiderable advantages over open appendectomy; such advantages include less postoperative pain, better cosmetic results, a shorter hospital stay, and a lower complication rate [1]. However, LA has been routinely performed under general anesthesia with endotracheal intubation despite the several disadvantages of general anesthesia compared to regional anesthesia, including hemodynamic instability, postoperative nausea and vomiting (PONV), increase in the requirement for postoperative analgesia, complications related to intubation or extubation, and a sore throat postoperatively $[2,3]$.

Although many reports of laparoscopic inguinal hernia repair and cholecystectomy under regional anesthesia have been published [4-7], few studies have involved regional anesthesia for LA [8]. Moreover, laparoscopic surgery under regional anesthesia in previous studies was commonly associated with problems such as referred shoulder pain secondary to intra-abdominal carbon dioxide $\left(\mathrm{CO}_{2}\right)$ pneumoperitoneum; patient anxiety, pain, and discomfort; and inadequate sedation.

Dexmedetomidine, a selective $\alpha_{2}$-aderenoreceptor agonist, possesses sedative, analgesic, anxiolytic, and hemodynamicstabilizing properties with preservation of the ventilatory drive [9]. In addition, intravenous dexmedetomidine administration for spinal anesthesia prolongs the effects of the sensory and motor block and provides a sedative effect [10].

Thus, it is a useful and safe adjunct in regional anesthesia. Based on the characteristics of dexmedetomidine and studies published previously [4-8] that performed laparoscopic surgeries under regional anesthesia, we designed a preliminary study to assess the feasibility and safety of performing LA under spinal anesthesia with intravenous dexmedetomidine infusion.

\section{Materials and Methods}

This prospective observational study was conducted in a university hospital from August 2013 to December 2013. This study was approved by the Institutional Review Board of our hospital, and written informed consent was obtained from 26 patients with an American Society of Anesthesiologists physical status score of I and II undergoing LA before the study began. The exclusion criteria were as follows: (1) infection at the spinal anesthesia injection site, (2) coagulopathy or other bleeding diathesis, (3) spinal deformity or severe back pain, (4) history of bradyarrhythmia, (5) obesity (body mass index $>30 \mathrm{~kg} / \mathrm{m}^{2}$ ), (6) patients $<20$ or $>65$ years old, (7) history of allergy or hypersensitivity to local anesthetics, and (8) recent administration of sedative drugs or $a$-adrenergic antagonists, and (9) perforated appendicitis.

All patients were informed about the possibility of conversion to general anesthesia at any time intraoperatively if they requested it because of persistent pain or discomfort despite administration of intravenous analgesics or sedatives.

Upon the patient's arrival in the operating room, routine monitoring, including noninvasive automated blood pressure, pulse oximetry, and electrocardiography, was begun without premedication. Oxygen was administered at $6 \mathrm{~L} / \mathrm{min}$ via a face mask, and end-tidal carbon dioxide monitoring was performed. Before induction of spinal anesthesia, $500 \mathrm{ml}$ of crystalloid fluid were administered via a peripheral vein with an 18-gauge intravenous catheter (BD Angiocath Plus, Becton Dickinson Korea, Seoul, Korea). Spinal anesthesia was induced in the right lateral decubitus position using a 25-gauge Quincke spinal needle positioned at the midline between L4-5. Upon confirmation of the intrathecal position of the needle by leakage and slight aspiration of cerebrospinal fluid, the intrathecal anesthetics (hyperbaric bupivacaine $0.5 \%$ with fentanyl $10 \mu \mathrm{g}$ ) were introduced. The amount of hyperbaric bupivacaine $0.5 \%$ was determined empirically by the anesthesiologist according to the height, weight, and age of the patient and in consideration of our target sensory level of anesthesia (T4). After administration of the intrathecal anesthetics, the patient's position was immediately changed to supine. The sensory block level was assessed by the pinprick test using a 24-gauge hypodermic needle, while the motor block level was assessed by the modified Bromage scale $(0=$ no paralysis; 1 = unable to raise extended leg; 2 = unable to flex knee; $3=$ unable to flex ankle) [11] and recorded $10 \mathrm{~min}$ after placement in the supine position. Simultaneously with the spinal block procedure, dexmedetomidine was infused at a loading dose of $1 \mu \mathrm{g} / \mathrm{kg}$ for $10 \mathrm{~min}$ followed by an infusion at $0.6 \mu \mathrm{g} / \mathrm{kg} / \mathrm{h}$ until the laparoscope was removed after appendectomy. The level of sedation was evaluated immediately before dexmedetomidine loading-dose infusion (baseline) and during the operation using the bispectral index (BIS). If any patient experienced pain or discomfort, fentanyl (50-100 $\mu \mathrm{g})$ with or without ketamine $(0.5$ $\mathrm{mg} / \mathrm{kg}$ ) was administered intravenously. Besides co-administration of fentanyl for analgesic effects, additional ketamine $(0.5$ $\mathrm{mg} / \mathrm{kg}$ ) was injected at the patient's request for sedation or in case of a BIS $>85$ despite a 20-min dexmedetomidine infusion. Hypotension was defined as either $>30 \%$ decrease in systolic blood pressure compared with preanesthetic pressure or systolic blood pressure $<90 \mathrm{mmHg}$ and was treated with $50-100 \mathrm{ml}$ of intravenous crystalloid fluid replacement and a $5 \mathrm{mg}$ ephedrine bolus. Bradycardia was defined as a heart rate of less than 50 bpm and was treated with $0.5 \mathrm{mg}$ of intravenous atropine. All patients' complaints and side effects were recorded (e.g., referred shoulder pain, abdominal discomfort, hypotension, nausea, 
headache, etc.), and postoperative pain scores were assessed at 2 , 6,12 , and $24 \mathrm{~h}$ postoperatively using a 0 to $10 \mathrm{~cm}$ visual analog scale $(0=$ no pain, $10=$ worst pain imaginable) by a registered nurse who was blinded to the study. The overall degree of patient satisfaction was also assessed by an anesthesia resident who was unaware of the aim of the present study using a threepoint scale (good, moderate, and bad) on the first postoperative day. Surgery was performed by the same surgical team, and the surgeons applied the minimum possible intra-abdominal carbon dioxide pressure for the pneumoperitoneum at the request of the anesthesiologist. No other modifications of the technique were implemented.

\section{Results}

The demographic data are shown in Table 1.

A sensory level of T3, T4, T5, and T6 was obtained in 1, 12, 11 , and 2 patients, respectively. A modified Bromage scale score of 3,2 , and 1 was obtained in 16,9 , and 1 patient, respectively. The mean volume of intrathecal hyperbaric bupivacaine $0.5 \%$ administered was $14.1 \pm 1.4 \mathrm{mg}$ (range, $11-16 \mathrm{mg}$ ). The mean operative duration was $42.6 \pm 11.0 \mathrm{~min}$ (range, 25.0-70.0 $\mathrm{min}$ ). The mean anesthesia duration was $64.6 \pm 11.0 \mathrm{~min}$ (range, 50.0$85.0 \mathrm{~min}$ ). During the operation, the intra-abdominal $\mathrm{CO}_{2}$ gas pressure was maintained at 12,10,9, and $8 \mathrm{mmHg}$ in 2, 19, 3, and 2 patients, respectively.

Adverse effects observed during surgery are shown in Table 2. Seventeen patients received intravenous fentanyl or ketamine injections; seven patients required both. Twelve patients required

Table 1. Demographic Data

\begin{tabular}{lc}
\hline Sex $(\mathrm{M} / \mathrm{F})$ & $14 / 12$ \\
Age $(\mathrm{yr})$ & $36.1 \pm 14.0$ \\
Height $(\mathrm{kg})$ & $167.6 \pm 8.3$ \\
Weight $(\mathrm{cm})$ & $63.3 \pm 13.0$ \\
ASA status (I/II) & $19 / 7$ \\
\hline
\end{tabular}

Data are expressed as means \pm standard deviation or number of patients. ASA: American Society of Anesthesiologists.

Table 2. Adverse Effects Observed during Laparoscopic Appendectomy

\begin{tabular}{lc}
\hline & No. of patients $(\mathrm{N}=26)$ \\
\hline Referred shoulder pain & $8(30.8)$ \\
Abdominal discomfort & $6(23.1)$ \\
Hypotension & $3(11.5)$ \\
Bradycardia & $7(26.9)$ \\
Nausea/vomiting & $1(3.8) / 0(0.0)$ \\
Anxiety & 0 \\
Respiratory depression & 0 \\
\hline
\end{tabular}

Data are expressed as numbers of patients (\%). Respiratory depression is defined as respiratory rate $<8 \mathrm{bpm}$. an intravenous fentanyl injection for management of referred shoulder pain or abdominal discomfort. The average fentanyl requirement in all patients was $35 \mu \mathrm{g}$ (range, $0-150 \mu \mathrm{g}$ ), and the median fentanyl requirement in patients who were given fentanyl was $50 \mu \mathrm{g}$ (interquartile range [IQR], 50-90 $\mu \mathrm{g}$ ). Twelve patients received ketamine injections; seven patients were coadministered fentanyl to manage pain or discomfort; five (19.2\%) had no pain or discomfort, but they were injected with ketamine following a decision by the attending anesthesiologist because they showed a BIS $>85$ despite a 20 min dexmedetomidine infusion. The average ketamine requirement in all patients was 24.8 mg (range, $0.0-110.0 \mathrm{mg}$ ), and the median ketamine requirement in patients who were given ketamine was $50 \mathrm{mg}$ (IQR, 32.5-67.5 mg). None of the patients reported hallucinations. The changes in the BIS over time are shown in Fig. 1. The BIS significantly decreased from 10 min after initiation of the loading dose for dexmedetomidine infusion compared with baseline $(\mathrm{P}<0.05)$. The changes in the BIS over time showed statistical significance $(\mathrm{P}<0.001)$.

Hypotension occurred in three patients, two of whom received $15 \mathrm{mg}$ of ephedrine; one received $10 \mathrm{mg}$. Bradycardia occurred in seven patients, and all were corrected by $0.5 \mathrm{mg}$ of atropine. One patient complained of nausea before intra-abdominal carbon dioxide pneumoperitoneum, but this subsided with $8 \mathrm{mg}$ of ondansetron and fluid administration.

No patient required conversion to general anesthesia, and all operations were completed laparoscopically without conversion to open surgery.

The postoperative pain score was $1.5 \pm 1.5$ (range, 0.0-5.0) 2 $\mathrm{h}$ after completion of the operation, $3.1 \pm 2.2$ (range, $0.0-8.0$ ) at $6 \mathrm{~h}, 2.5 \pm 1.7$ (range, $0.0-8.0$ ) at $12 \mathrm{~h}$, and $1.6 \pm 1.2$ (range, 0.0$6.0)$ at $24 \mathrm{~h}$.

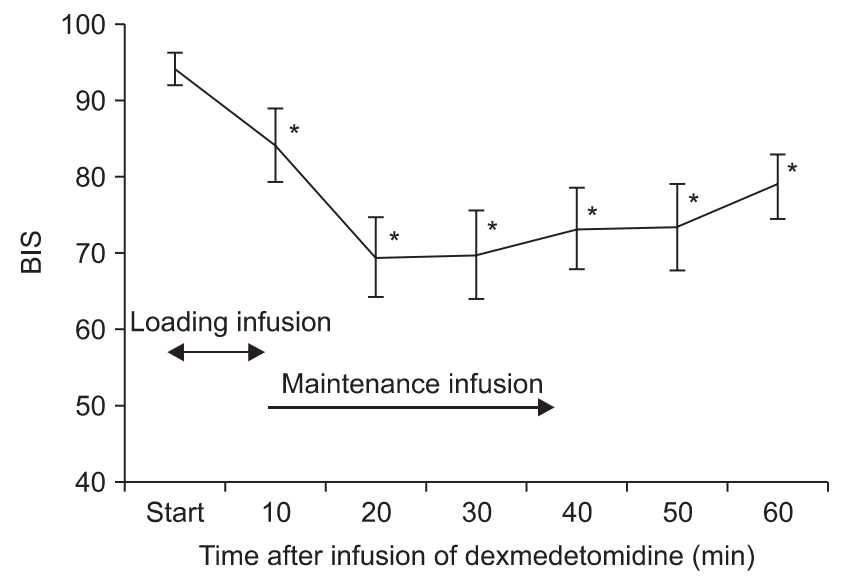

Fig. 1. Changes in bispectral index (BIS) after intravenous infusion of dexmedetomidine. BIS values decreased significantly compared to baseline beginning $10 \mathrm{~min}$ after infusion of dexmedetomidine. Data are means \pm standard deviations. ${ }^{*} \mathrm{P}<0.05$ compared to baseline. 
The degree of patient satisfaction was good, moderate, and poor in 14,10 , and 2 patients, respectively.

\section{Discussion}

In this study, 26 patients underwent LA under spinal anesthesia with intravenous dexmedetomidine infusion. Eight and six patients experienced referred shoulder pain and abdominal discomfort, respectively, but these conditions were manageable with fentanyl with or without ketamine injection. Bradycardia was observed in seven patients. There were no conversions to general anesthesia or open surgery.

Proper management of pain, discomfort, and anxiety during intra-abdominal carbon dioxide pneumoperitoneum is a major concern during the use of regional anesthesia for laparoscopic surgery. In particular, preventing and managing carbon dioxide pneumoperitoneum-induced shoulder pain is important during laparoscopic surgery under regional anesthesia. Postoperative shoulder tip pain resulting from diaphragm irritation after general anesthesia can be easily reduced by removing intraabdominal residual carbon dioxide gas, which can be accomplished by applying active aspiration via the trochars [12] or the lung recruitment maneuver at the end of surgery [13]. However, intraoperative shoulder tip pain during regional anesthesia is a leading cause of conversion to general anesthesia [5,7].

In comparison to previous studies [4,14], LA under spinal anesthesia differed markedly from laparoscopic hernia repair under regional anesthesia. During laparoscopic hernia repair, carbon dioxide gas is introduced into the extraperitoneal space, not the intra-abdominal cavity. In addition, the head-down tilt position is not required for surgery. Both intra-abdominal carbon dioxide gas insufflation and the head-down tilt position can cause and aggravate abdominal discomfort and referred shoulder tip pain [6]. Therefore, we infused dexmedetomidine with the expectation that its analgesic and sedative effects would resolve pain and discomfort during the carbon dioxide pneumoperitoneum without depressing respiration. Considering the pharmacokinetic characteristics of dexmedetomidine (distribution half-life of 6 min and terminal elimination half-life of $2 \mathrm{~h}$ ) [15], we infused intravenous dexmedetomidine from the spinal block procedure until deflation of the intra-abdominal carbon dioxide gas. Early preoperative infusion of dexmedetomidine, which has an anxiolytic effect, could explain the lack of anxiety in the present study.

In the present study, we used supplemental intravenous ketamine $(0.5 \mathrm{mg} / \mathrm{kg})$ not only for its sedative effect but also its analgesic effect. Although midazolam or propofol are commonly used for sedation during regional anesthesia, these drugs lack analgesic properties and they may aggravate hypotension and bradycardia when used in combination with dexmedetomidine during spinal anesthesia. Ketamine usually increases blood pressure, heart rate, and cardiac output [16]. Furthermore, the incidence of ketamine-related adverse effects, including emergence reactions, hallucinations, and nausea and vomiting decreased significantly with dexmedetomidine-ketamine compared with midazolam-ketamine [17]. Ketamine can be used as a supplement to regional anesthesia at doses of $0.1-0.5 \mathrm{mg} / \mathrm{kg}$ [18] or $0.2-0.8 \mathrm{mg} / \mathrm{kg}$ [16]. However, in our pilot study, too small a dose of ketamine did not guarantee efficacy for pain or discomfort management. Therefore, we determined $0.5 \mathrm{mg} / \mathrm{kg}$ as the dose to supplement ketamine in this study.

The optimal sensory block level for LA under spinal anesthesia has not been established. Thus, based on previous studies $[6,8]$, we determined the target sensory level to be T4 in this study. In addition, conventional doses of hyperbaric spinal anesthetic agents are not recommended for laparoscopy because the head-down tilt position can lead to cephalad spread of the spinal block, resulting in greater sympathetic block, bradycardia, and hypotension [19]. Therefore, we minimized the dose of hyperbaric bupivacaine to reduce the side effects of extensive sympathetic blockade and administered intrathecal fentanyl $(10 \mu \mathrm{g})$ to allow for a reduced dose of hyperbaric bupivacaine $0.5 \%$ and to provide adequate analgesia. However, despite the administration of a near-maximum dose of dexmedetomidine [20], 17 (65.4\%) patients required supplemental injection of fentanyl or ketamine for pain or discomfort management or a greater sedative effect. This finding may suggest that spinal anesthesia with intravenous dexmedetomidine alone is insufficient for adequate anesthesia during LA. However, the frequent use of supplemental drugs in this study can be explained by the fact that we did not restrict the degree of head-down tilt for surgery, resulting in the flow of blood or irritant fluids into the diaphragm and increasing the incidence of shoulder pain and abdominal discomfort compared with other studies $[6,8]$. Another explanation is that we administered fentanyl or ketamine to patients with mild pain or discomfort, patients with no complaints but with a BIS $>85$, as well as patients with moderate or severe pain. This was performed to create a comfortable surgical environment by removing the surgeon's concern about the patient and to prevent aggravation of the patient's pain. Avoidance of extreme degrees of head-down tilt, low-pressure pneumoperitoneum $(5-7 \mathrm{mmHg})$, and the use of nitrous oxide insufflation gas instead of carbon dioxide gas might be helpful to reduce the use of supplemental analgesic and sedative drugs during the carbon dioxide pneumoperitoneum $[19,21]$.

Hypotension and bradycardia are common adverse effects associated with dexmedetomidine as well as with spinal anesthesia. The incidence of dexmedetomidine-related hypotension and bradycardia were 30 and $9 \%$, respectively, in a phase-III study of 401 patients [15]. The incidence of hypotension, but not 
of bradycardia, increases as the dose of dexmedetomidine increases [22]. In contrast, a meta-analysis study showed that dexmedetomidine use during spinal anesthesia is associated with more frequent bradycardia but did not increase the incidence of hypotension [10].

The low incidence of hypotension and high incidence of bradycardia in the present study may have been due mainly to the effects of pneumoperitoneum. At intra-abdominal pressures of $<15 \mathrm{mmHg}$, venous return, cardiac filling pressure, and cardiac output are increased as blood is squeezed from the splanchnic venous bed and by sympathetically mediated peripheral vasoconstriction [23]. In addition, insertion of the Veress needle or trocar and pneumoperitoneum-induced peritoneal stretching can cause vagal stimulation, which can lead to significant bradycardia [24].

In this study, only one patient complained of nausea during anesthesia and none of the patients reported PONV. This result supports the findings of Sinclair et al. [25], who found that patients receiving regional anesthesia had an 11-fold decreased risk for PONV compared with those receiving general anesthesia.

There were several limitations to this study. First, this preliminary study was initially designed to assess the feasibility and safety of performing LA under spinal anesthesia with an intravenous dexmedetomidine infusion; therefore, it did not include a placebo or comparison group. Further studies with a placebo or comparison group are needed to compare the efficacy of dexmedetomidine infusion or reduce the problems related to spinal anesthesia with dexmedetomidine infusion. Second, we did not evaluate the effects of various maintenance doses of dexmedetomidine $(0.2-0.7 \mu \mathrm{g} / \mathrm{kg} / \mathrm{h})$. Thus, the optimal maintenance dose of dexmedetomidine for LA remains unknown. Third, we excluded obese patients (body mass index $>30 \mathrm{~kg} / \mathrm{m}^{2}$ ). Regional anesthesia may be more suitable than general anesthesia in these patients because obese patients often have comorbidities such as ischemic heart disease, hypoventilation syndrome, and metabolic disorders [26]. Dexmedetomidine may also be beneficial in obese patients who are at risk of respiratory depression because it attenuates postoperative pain and thus reduces the requirement for opioids [27]. However, obese patients have a high incidence of gastroesophageal reflux disease, which can be aggravated by increased intra-abdominal pressure [28]. Obese patients were therefore excluded from our study because of concern regarding the potential for aspiration of gastric contents.

In conclusion, this study has shown that spinal anesthesia with dexmedetomidine infusion may be applicable to LA and help to avoid intubation-related complications. However, supplemental analgesic and sedative management during pneumoperitoneum and careful attention to the potential development of bradycardia are needed for successful anesthesia.

\section{References}

1. Li X, Zhang J, Sang L, Zhang W, Chu Z, Li X, et al. Laparoscopic versus conventional appendectomy - a meta-analysis of randomized controlled trials. BMC Gastroenterol 2010; 10: 129.

2. Ozgün H, Kurt MN, Kurt I, Cevikel MH. Comparison of local, spinal, and general anaesthesia for inguinal herniorrhaphy. Eur J Surg 2002; 168: 455-9.

3. Sinha R, Gurwara AK, Gupta SC. Laparoscopic total extraperitoneal inguinal hernia repair under spinal anesthesia: a study of 480 patients. J Laparoendosc Adv Surg Tech A 2008; 18: 673-7.

4. Lal P, Philips P, Saxena KN, Kajla RK, Chander J, Ramteke VK. Laparoscopic total extraperitoneal (TEP) inguinal hernia repair under epidural anaesthesia: a detailed evaluation. Surg Endosc 2007; 21: 595-601.

5. Hamad MA, El-Khattary OA. Laparoscopic cholecystectomy under spinal anesthesia with nitrous oxide pneumoperitoneum: a feasibility study. Surg Endosc 2003; 17: 1426-8.

6. van Zundert AA, Stultiens G, Jakimowicz JJ, Peek D, van der Ham WG, Korsten HH, et al. Laparoscopic cholecystectomy under segmental thoracic spinal anaesthesia:a feasibility study. Br J Anaesth 2007; 98: 682-6.

7. Lee JH, Huh J, Kim DK, Gil JR, Min SW, Han SS. Laparoscopic cholecystectomyunder epidural anesthesia: a clinical feasibility study. Korean J Anesthesiol 2010; 59: 383-8.

8. Mane RS, Patil MC, Kedareshvara KS, Sanikop CS. Combined spinal epidural anesthesia for laparoscopic appendectomy in adults: A case series. Saudi J Anaesth 2012; 6: 27-30.

9. Grewal A. Dexmedetomidine: New avenues. J Anaesthesiol Clin Pharmacol 2011; 27: 297-302.

10. Niu XY, Ding XB, Guo T, Chen MH, Fu SK, Li Q. Effects of intravenous and intrathecal dexmedetomidine in spinal anesthesia: a metaanalysis. CNS Neurosci Ther 2013; 19: 897-904.

11. Bromage PR, Burfoot MF, Cromwell DE, Pettigrew RT. Quality of epidural blockade. I: Influence of physical factors. Br J Anaesth 1964; 36: 342-52.

12. Das K, Karateke F, Menekse E, Ozdogan M, Aziret M, Erdem H, et al. Minimizing shoulder pain following laparoscopic cholecystectomy: a prospective, randomized, controlled trial. J Laparoendosc Adv Surg Tech A 2013; 23: 179-82. 
13. Phelps P, Cakmakkaya OS, Apfel CC, Radke OC. A simple clinical maneuver to reduce laparoscopy-induced shoulder pain: a randomized controlled trial. Obstet Gynecol 2008; 111: 1155-60.

14. Sung TY, Kim MS, Cho CK, Park DH, Kang PS, Lee SE, et al. Clinical effects ofintrathecal fentanyl on shoulder tip pain in laparoscopic total extraperitoneal inguinalhernia repair under spinal anaesthesia: a double-blind, prospective, randomized controlled trial. J Int Med Res 2013; 41: 1160-70.

15. Bhana N, Goa KL, McClellan KJ. Dexmedetomidine. Drugs 2000; 59: 263-8.

16. Reves JG, Glass P, Lubarsky DA, McEvoy MD, Martinez-Ruiz R. Intravenous Anesthetics. In: Miller's Anesthesia. 7th ed. Edited by Miller RD: Philadelphia, Elsevier Churchill Livingstone. 2009, pp 742-7.

17. Koruk S, Mizrak A, Gul R, Kilic E, Yendi F, Oner U. Dexmedetomidine-ketamine and midazolam-ketamine combinations for sedation in pediatric patients undergoing extracorporeal shock wave lithotripsy: a randomized prospective study. J Anesth 2010; 24: 858-63.

18. Kohrs R, Durieux ME. Ketamine: teaching an old drug new tricks. Anesth Analg 1998; 87: 1186-93.

19. Gerges FJ, Kanazi GE, Jabbour-Khoury SI. Anesthesia for laparoscopy: a review. J Clin Anesth 2006; 18: 67-78.

20. Gerlach AT, Dasta JF. Dexmedetomidine: an updated review. Ann Pharmacother 2007; 41: 245-52.

21. Spivak H, Nudelman I, Fuco V, Rubin M, Raz P, Peri A, et al. Laparoscopic extraperitoneal inguinal hernia repair with spinal anesthesia and nitrous oxide insufflation. Surg Endosc 1999; 13: 1026-9.

22. Song J, Kim WM, Lee SH, Yoon MH. Dexmedetomidine for sedation of patients undergoing elective surgery under regional anesthesia. Korean J Anesthesiol 2013; 65: 203-8.

23. Odeberg S, Ljungqvist O, Sevenberg T, Gannedahl P, Backdahl M, von Rosen A, et al. Haemodynamic effects of pneumoperitoneum and the influence of posture during anaesthesia for laparoscopic surgery. Acta Anaesthesiol Scand 1994; 38: 276-83.

24. Sprung J, Abdelmalak B, Schoenwald PK. Recurrent complete heart block in a healthy patient during laparoscopic electrocauterization of the fallopian tube. Anesthesiology 1998; 88: 1401-3.

25. Sinclair DR, Chung F, Mezei G. Can postoperative nausea and vomiting be predicted? Anesthesiology 1999; 91: 109-18.

26. Lotia SH, Bellamy M. Anaesthesia and morbid obesity. Contin Educ Anaesth Crit Care 2008; 8: 151-6.

27. Hofer RE, Sprung J, Sarr MG, Wedel DJ. Anesthesia for a patient with morbid obesity using dexmedetomidine without narcotics. Can J Anaesth 2005; 52: 176-80.

28. Friedenberg FK, Xanthopoulos M, Foster GD, Richter JE. The association between gastroesophageal reflux disease and obesity. Am J Gastroenterol 2008; 103: 2111-22. 